\title{
A Basic Study on the Analysis of Utilization and Awareness According to the Location of Urban Geriatric Hospitals
}

\author{
Jeongyoon $\mathrm{Kim}^{1}$, Yujin $\mathrm{Choi}^{2}$ and Heangwoo $\mathrm{Lee}^{3^{*}}$ \\ Major of Space Design, College of Design, Sangmyung University, Korea \\ 1201820215@sangmyung.kr, ${ }^{2}$ myna1106@naver.com,32hw@smu.ac.kr
}

\begin{abstract}
The number of urban silver towns that can be linked to cultural, convenience, and medical facilities in a city has been gradually increasing in order to solve aging problems, which has become serious recently due to the aging of society. However, urban silver towns have become inappropriate elements for the elderly people who use them in terms of accessing the diversity of the city due to insufficient considerations in the area of urban planning. The aim of this study is to select one urban silver town currently in operation to establish preliminary data, and the conclusions reached are as follows. The benefits of the urban silver town can be capitalized while increasing its utility through proper linkage with adjacent surrounding facilities. However, the urban silver town selected in this study was low in the indicators of connectivity, control value, and intelligibility, which are the space syntax. Such aspects cause difficulty for elderly people using facilities adjacent to the silver town. However, it is considered possible to improve the intelligibility by locating the urban silver town at the center of the moving line in terms of urban planning, in order to improve accessibility to surrounding facilities. This will raise the availability of the facilities adjacent to elderly people, increasing the benefits of the urban silver towns.
\end{abstract}

Keywords: Silvertown, Locational characteristics cognition, Spatial accessibility, Space syntax

\section{Introduction}

Recently, 'urban silver towns', which are charged mixed-use cultural and residential complexes, have been increasing in order to solve the aging problems and meet the demands of elderly people over age 60 . The urban silver towns can link to various medical, traffic, and cultural facilities located in a city, so its preference is higher than that of other facilities for the elderly [1][2]. However, various studies being carried out currently are mainly focused on indoor facilities [3]. Such studies focusing on indoor facilities do not consider the physical characteristics of elderly people, and ignore the difficulty elderly people have in accessing adjacent cultural and educational facilities. In addition, no study has been carried out regarding silver towns in terms of the hierarchy of city that may become the grounds for urban planning [4][5].

Therefore, the purpose of this study is to determine the connectivity of the silver towns to surrounding medical and cultural facilities and establish basic data for designing the urban

Article history:

Received (May 28, 2020), Review Result (June 30, 2020), Accepted (August 6, 2020) 
silver towns by analyzing the hierarchy of the city for an actual silver town which is in operation currently.

\section{Consideration of silver town and space syntax}

\subsection{Consideration of Elderly People and Silver Town}

The International Association of Gerontology and Geriatrics defines an elderly person as 'a person whose psychological, biological, environmental, and behavioral changes are in the process in complex form through interaction.' In this regard, the space for the elderly should be planned by appropriately considering accessibility and cognitivity. In other words, spaces for elderly people should consider their physical, psychological, and cognitive characteristics. Facilities for the elderly can be classified into housing facilities, medical facilities, leisure facilities, and home care facilities [6][7].

The functions of such facilities for the elderly have recently been diversified due to a change in the perception of older people. Such facilities are being developed beyond the concept of care into multi-purpose cultural spaces that local residents as well as people of all ages can share in addition to their previous food, clothing, and shelter care and leisure functions. In addition, the number of urban silver towns is gradually increasing in terms of using adjacent cultural and medical facilities. Therefore, this study aims to analyze the locations of urban silver towns as well as the accessibility and awareness of adjacent medical and cultural facilities in order to minimize difficulties in using facilities near the urban silver towns provided with various systems for the elderly by improving their accessibility and awareness [8].

\subsection{Consideration of space syntax}

In this study, space syntax was presented as the analysis methodology. Space syntax methodologies can be divided into the method using the axis line and the method using the convex, and the method using the axis line was selected in this study in order to determine the urban hierarchy of the silver towns. The grounds for selecting the space syntax as the analysis method in this study are as follows. The space syntax is a series of technologies used to quantitatively analyze the relation and characteristics of each space. An analysis of accessibility, passageway, and cognitivity based on the link between unit spaces is possible.

The assessment indicators and detailed contents drawn through the space syntax are as follows. First, connectivity means the number of connections from a specified axis line to a surrounding axis line, and an axis line with high connectivity has a characteristic of being located at the center according to the hierarchy of space. If the connectivity is high, congestion can be expected, since the frequency of use is high. Second, the control value indicates the influence over surrounding moving lines; if an axis line has a high control value, it means that it is easy to move to a neighboring axis line. Third, integration refers to the number of axis lines to approach from a certain axis line to an adjacent axis line. In addition, the integration features that the relationship between a certain axis line and the axis line of the whole space is quantified. Fourth, intelligibility means the interrelationship between integration and local integration. The spatial cognition is higher as the correlation between these two indicators is higher. This is the result reflected in the way that the local integration is the intelligibility drawn within the range recognized by human beings [9][10].

\section{Analysis method and result}




\subsection{Target selection}

In this study, the following were considered in order to set the target. First, the target was limited to silver towns that were established after 2000 and are currently in operation. The timeline of after 2000 was set in this study because there was a substantial increase in the elderly population during this period, raising interest, and modernization was also carried out. Second, only urban silver towns were considered as the target for this study. Ultimately, the target of this study was limited to a silver town located in Seoul, Korea. As a result, The Signum Haus, an urban silver town located in Gangnam-gu, was selected as the analysis target. After the beginning of this construction in 2015, The Signum Haus was opened in 2017, and seniors over the age of 60 and under 85 could move in. The space is divided into a silver town where elderly people who can live independently reside and a nursing home where elderly people who require care 24 hours a day reside, and can accommodate a total of 230 couples. With three stories below and five above ground, the total floor area of this building is $30,936 \mathrm{~m}^{2}$ and five room types including single type and couple type are available. The Signum Haus is located in a place adjoining medical, cultural, and natural environments. This place was selected because various facilities and convenient traffic facilities were available nearby. The complete view of The Signum Haus selected in this study is as shown in [Figure 1].

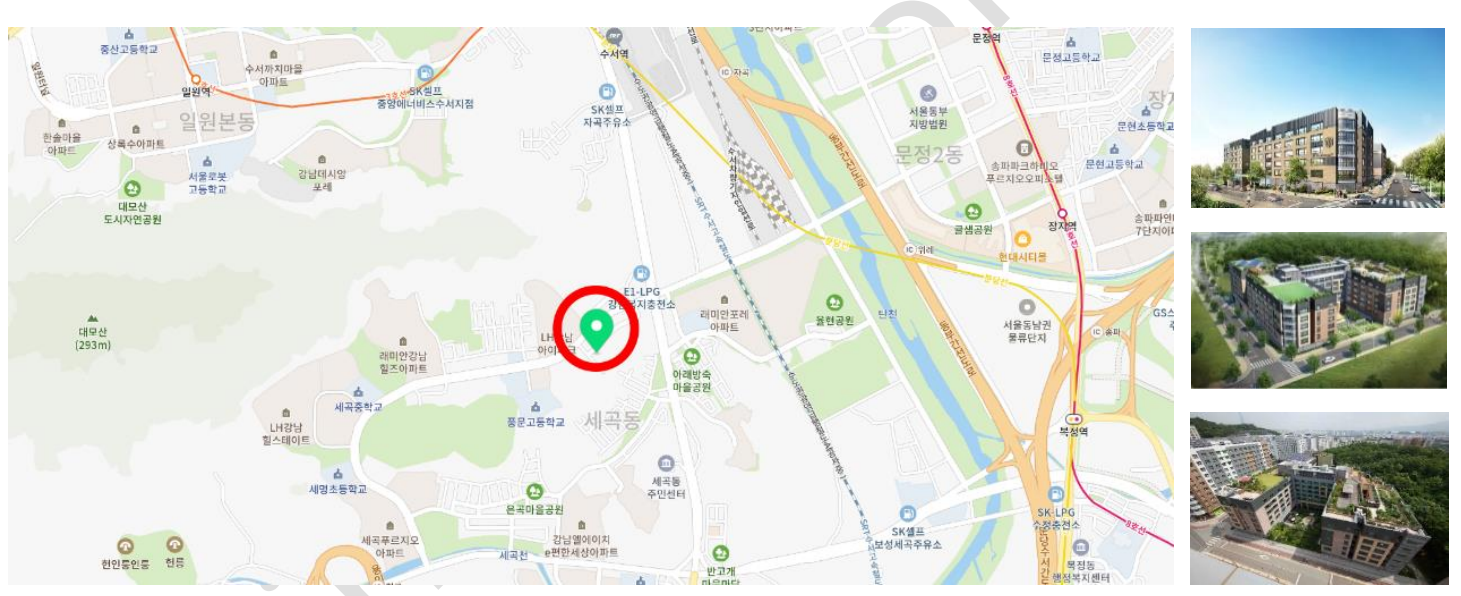

Figure 1. Location and complete view of the signum Haus

\subsection{Analysis method}

This study was a location analysis of an urban silver town in terms of urban planning, and it was carried out using the following method.

First, the medical and convenient facilities located within a $5 \mathrm{~km}$ radius from the relevant silver town were drawn in order to analyze the relationship between the silver town and surrounding facilities. Second, the urban structure based on the silver town was analyzed by drawing the moving lines within $5 \mathrm{~km}$. The moving lines selected in this study were limited to the ones where the entry of a vehicle was possible. Third, the space syntax was applied based on the induced moving lines, and the connectivity drawn through such process was verified in many studies, so it was presumed that this method was also appropriate for this study. As mentioned earlier, the S3 axial tool was used for the analysis. 


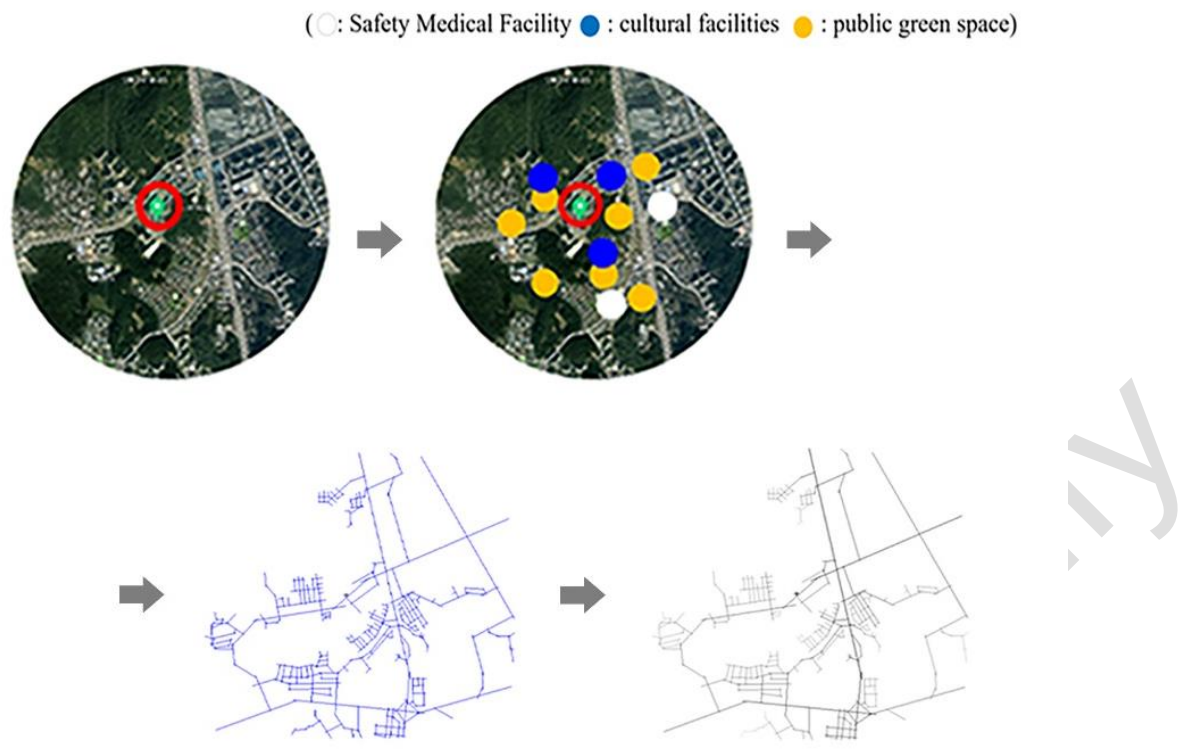

Figure 2. Method of analysis

\subsection{Analysis result and discussion}

The results of the location analysis of the urban silver town selected for this study in terms of urban planning are as follows.

First, the axis lines within a $5 \mathrm{~km}$ radius selected based on the urban silver town in this study are as shown in [Table 1] and [Figure 3]. More than 250 axis lines were drawn, but were somewhat complex due to the urban characteristics. This aspect may cause inconvenience to the elderly with low spatial cognition. Second, the connectivity of an axis line adjacent to the urban silver town is higher than the average connectivity of the axis line as shown in Table 1. As it is not in the high axis line within the top $10 \%$, this indicates that the axis line adjacent to the urban silver town is not located at the center according to the structure of the moving line. It is considered that this is the result of considering the cost efficiency of the urban silver town in the initial planning. However, this silver town is adjacent to the axis line with high connectivity, covering its low connectivity. Third, the urban silver town selected in this study shows a low control value as shown in Table 1. Since the control value quantifies the accessibility to adjacent areas, The Signum Haus has limited accessibility to adjacent medical and convenient facilities. Fourth, the intelligibility including the urban silver town within a $5 \mathrm{~km}$ radius set through this study is less than 0.6 as shown in Table 1 , which is inappropriate for elderly people. Generally, the structure of a moving line with a value less than 0.6 has low awareness and may cause inconvenience. In particular, it is considered that elderly people may experience greater difficulty due to their characteristics of low cognitive ability.

The above contents can be summarized as follows. Many considerations are involved when planning a facility for elderly people with decreased physical and spatial abilities. However, not enough consideration has been given in the area of urban planning, so many silver towns may cause inconvenience to elderly people. In this study, the quantitative relationship between an actual urban silver town and surrounding facilities was examined. Our analysis found that a silver town should be located at the center of urban structures, and a close 
examination of ways to increase the rate of space use and recognition by elderly people is also necessary to maximize the use of adjacent facilities that are beneficial to residents of the urban silver town. By drawing the quantitative relationship between the urban silver town and surrounding facilities, the use of such facilities by residents can be maximized.

Table 1. The signum Haus analysis result

\begin{tabular}{|c|c|c|}
\hline \multicolumn{2}{|r|}{ Analysis method } & Result value \\
\hline \multicolumn{2}{|r|}{ Axial line count } & 256 \\
\hline \multirow{3}{*}{ Connectivity } & Average & 2.9 \\
\hline & Maximum value & 12 \\
\hline & Connectivity diagram of the axial line adjacent to Silver Town & 3 \\
\hline \multirow{3}{*}{ Cotrol Value } & Average & 1 \\
\hline & Maximum value & 3.7 \\
\hline & A control chart of the vicinity of Silver Town & 0.87 \\
\hline \multicolumn{2}{|r|}{ Intellingibility } & 0.458 \\
\hline
\end{tabular}

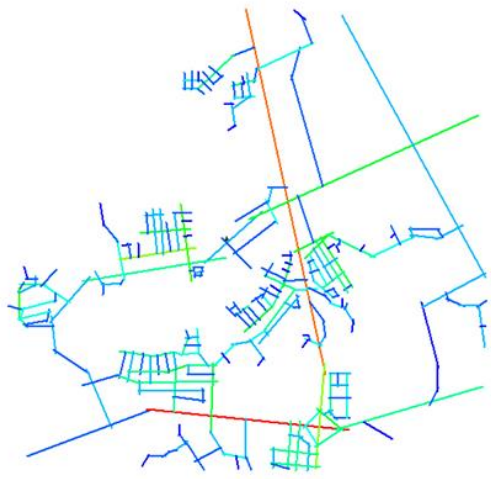

a) Connectivity

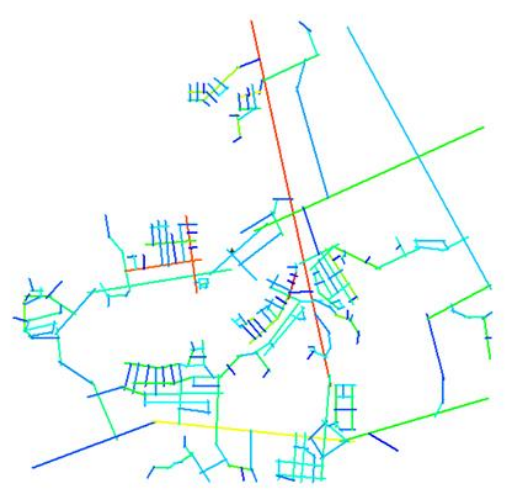

b) Control Value

Figure 3. Connectivity \& control value

\section{Conclusion}

This study aimed to analyze the locations of urban silver towns from an urban planning perspective, and the appropriateness of the location in terms of urban planning was verified based on an urban silver town in operation. The conclusions of this study are as follows.

First, more than 250 axis lines are shown within a $5 \mathrm{~km}$ radius in the urban silver town selected through this study, and these axis lines create somewhat complicated moving lines that may cause inconvenience to the elderly.

Second, the connectivity of an axis line adjacent to the urban silver town is slightly low, and this indicates that the axis line adjacent to the urban silver town is not located at the center according to the structure of the moving line. This is the result of a cost saving measure 
in the initial construction of the urban silver town that may cause inconvenience to elderly people.

Third, the control value of the selected urban silver town is low, and it is expected that the availability of facilities adjacent to the silver town will be low due to its low accessibility to surrounding facilities.

Fourth, the intelligibility including the urban silver town within a $5 \mathrm{~km}$ radius set through this study is low, which is inappropriate for elderly people. This indicates that it is necessary to consider the use and accessibility of space in planning the urban silver town. This study has significance in that it establishes relevant basic data by analyzing the appropriateness of the urban silver town in terms of urban planning. However, this study has a limitation in that the physical distance was not reflected in the axial map of space syntax used in this study. Therefore, various studies to address such limitation should be carried out in future.

\section{References}

[1] H. S. Yoon, "Analysis of the degree of community-aged affinity for the creation of a generation-integrated super-aged community: focused on yeongdeungpo-gu and yong," Hallym Journal of Aging Studies, vol.6, no.1, pp.25-47, (2018) DOI: 10.35187/HJAS.2018.6.1.25

[2] M. J. Kim and J. Y. Hwang, "A study on the long-term care insurance system prepare for the super-aged society," Journal of the Korea Academia-Industrial cooperation Society, vol.20, no.10, pp.395-405, (2019) DOI: $10.5762 /$ KAIS.2019.20.10.395

[3] J. G. Kim, "A study on the current status and system of the elderly medical and welfare facilities with the subjects in Busan," Journal of the Korean Society of Civil Engineers D, vol.30, no.6, pp.685-695, (2010)

[4] Y. S. Yoo, "Case study on the current status of senior workers' human rights abuses," Korean Society of Gerontological Social Welfare, vol.0, no.66, pp.37-54, (2014)

[5] H. J. Choi, "A longitudinal study on predictors of elderly employment (comparing young-old with old-old age group). a panel logit approach," Korean Society of Gerontological Social Welfare, vol.73, no.3, pp.113-141, (2018)

[6] Y. C. Lee and J. H. Lee, "A study on residents preference and willing to move in regarding to mixing of senior housing types in the regeneration of housing complex based on survey \& anslysis - focused on bundang new town -," Journal of the Architectural Institute of Korea Planning \& Design, vol.30, no.1, pp.3344, (2014)

[7] K. S. Baek and Y. S. Kwon, "The implemental factors of senior welfare center on leisure satisfaction in the elderly,” Korean Journal of Gerontological Social Welfare, vol.0, no.51, pp.321-339, (2011)

[8] S. K. Chai and K. S. Ha, "The preference of the silver town based on the psychological variances - mainly about the life style between from 30 s to 60 s, "Journal of the Korea contents association, vol.13, no.8, pp.211228, (2013)

[9] Y. R. Kim and J. W. Choe, "An analysis of museum exhibition space using space syntax theory," Journal of the Korea Institute of Spatial Design, vol.14, no.2 pp.81-90, (2019)

[10] S. H. Hwang, K. J. Kim, and J. H. Yoo, "A study on the typology of spatial organization in convention by spatial syntax. journal of the korea institute of spatial design," vol.8, no.4 pp.73-81, (2013) 